\title{
48,XYYY syndrome
}

INSERM

\section{Source}

INSERM. (1999). Orphanet: an online rare disease and orphan drug data base. 48, XYYY syndrome. ORPHA:99329

$48, X Y Y Y$ syndrome is a rare $\mathrm{Y}$ chromosome number anomaly that affects only males and is characterized by mild-moderate developmental delay (especially speech), normal to mild intellectual disability, large, irregular teeth with poor enamel, tall stature and acne. Radioulnar synostosis and clinodactyly have also been associated. Boys generally present normal genitalia, while hypogonadism and infertility is frequently reported in adult males. 